\section{Editorial}

Check for updates

\title{
Transition to Global Index and Digital Publication
}

\section{Sun-Chul Hwang $\mathbb{D}$, Editor-in-Chief, Korean Journal of Neurotrauma}

Department of Neurosurgery, Soonchunhyang University Bucheon Hospital, Bucheon, Korea

The remarkable changes are facing in the Korean Journal of Neurotrauma (KJNT) this year. From April 2019, KJNT has been registered in Scopus and the articles are digitally processed for the publication. The publication workflow has been totally updated. It is very honorable to be a journal indexed in the global company. And also KJNT become an international journal influencing the development of the neurotraumatology field. This issue (volume 15 issue 1) will be the first one in the KJNT indexed in the Scopus and 11 articles in this issue will be managed at the global company for assessing the impact in our field. The upcoming articles in KJNT will be also visualized in Scopus. And online publication first is also remarkable turning-point in our journal. The publication process will be faster than printing-based one and the research works will be opened to the public anytime and anywhere as soon as review processes are completed.

Our journal was first born in 2005 as an official journal of the Korean Neurotraumatology Society. It has continuously grown and expanded after the birth. Now, it is also an official journal of the Korean Spinal Cord Society. It could be said that KJNT is now a leading journal in the field of neurotrauma. As KJNT steps into an international journal from a domestic one, it faces more challenges. Most of all, it gets pressure for the quality improvement. The advancement of article quality and quantity is mandatory to keep it as a renowned international journal. And editorial works, ethic requirement, and publication process should meet the global standards. Quality improvement should be taking and keeping with all the efforts. The digital publication first is one of the process for achieving a quality improvement. We let the changes be shown in the online journal.

Conflict of Interest

The author has no financial conflicts of interest.
To get here of our journal, I specially express my thanks to the editorial members and all the reviewers. They all deserve to get praised. KJNT invites more young researchers for review of manuscripts. Peer review must be critical for all manuscripts. Thanks to the voluntary intellectual contribution of all the reviewers, KJNT can progress steadily. And I also thank Ms. Eun-Ae Jung, to help complete manuscript editing and advise the journal administration. The XMLink company takes the charge for digital editing and printing of the manuscripts. I am sure the company will be a best partner for stepping up the publication quality. Dedicated efforts of all the participants result in global index and digital publication of our journal. You are one of the participants and we all have taken a part that KJNT goes further. 